Check for updates

Cite this: RSC Adv., 2017, 7, 50343

Received 18th September 2017 Accepted 23rd October 2017

DOI: 10.1039/c7ra10351d

rsc.li/rsc-advances

\title{
Thermoregulated phase-separable rhodium nanoparticle catalyst for selective hydrogenation of $\alpha, \beta$-unsaturated aldehydes and ketones $\dagger$
}

\author{
Xiuru Xue, (D) Mingming Niu, Yicheng Xu and Yanhua Wang (D)*
}

\begin{abstract}
Thermoregulated phase-separable Rh nanoparticles (abbreviated as TPS- $\mathrm{Rh}_{\text {nano }}$ ) were found to be efficient catalysts for selective hydrogenation of $\mathrm{C}=\mathrm{C}$ bonds in $\alpha, \beta$-unsaturated aldehydes and ketones with a selectivity of $>99 \%$ at $>99 \%$ conversion. More importantly, the catalyst could be easily separated by simple phase separation and reused directly eight times without evident loss in activity and selectivity.
\end{abstract}

Soluble transition-metal nanoparticles have drawn much attention because of their high catalytic activity and excellent selectivity. However, the direct separation and recovery of these nanoparticles from the products in homogeneous catalytic reactions have always been technical problems that have needed to be solved for the past few decades..$^{1-4}$ Recently, based on our discovery that the polyether chain-based quaternary ammonium salt ionic liquids $\left[\mathrm{CH}_{3}\left(\mathrm{OCH}_{2} \mathrm{CH}_{2}\right)_{n} \mathrm{~N}^{+} \mathrm{Et}_{3}\right]\left[\mathrm{CH}_{3} \mathrm{SO}_{3}{ }^{-}\right]$ ( $\left.\mathrm{IL}_{\mathrm{PEG}}, n=12,16,22\right)$ exhibit electrosteric stabilization for nanoparticles and a distinctive critical solution temperature (CST) property in toluene and $n$-heptane mixtures, we have established thermoregulated phase-separable catalytic system (TPSCS) involving soluble transition-metal nanoparticles. ${ }^{5}$ The basic principle of TPSCS was described in Fig. 1. When temperature is lower than the CST, the lower $\mathrm{IL}_{\mathrm{PEG}}$ stabilized nanoparticle catalyst phase is immiscible with the upper mixed solvents phase containing substrate. Excitingly, once the reaction temperature is increased beyond the CST, the two-phase system becomes transparent and homogeneous which allows the reaction runs smoothly. After reaction, the homogeneous system returns into two-phase again at the temperature lower than CST. Therefore, the lower nanoparticle catalyst phase can be separated easily from the upper product phase by simple phase separation, and the catalyst can be reused in the next cycle. Obviously, such a catalytic system takes advantages of both classical homogeneous and heterogeneous systems. Till now, the TPSCS has been applied successfully for the hydrogenation of olefins, ${ }^{6}$ selective hydrogenation of 1,5-cyclooctadiene, ${ }^{5}$ Heck reaction ${ }^{7}$ and hydroaminomethylation of 1-octene ${ }^{8}$ with high catalytic efficiency and good recyclability.

State Key Laboratory of Fine Chemicals, Dalian University of Technology, Dalian 116024, PR China. E-mail: yhuawang@dlut.edu.cn; Fax: +86 411 84986033; Tel: +8641184986033

$\dagger$ Electronic supplementary information (ESI) available. See DOI: $10.1039 / \mathrm{c} 7 \mathrm{ra} 10351 \mathrm{~d}$
The selective hydrogenation of $\mathrm{C}=\mathrm{C}$ or $\mathrm{C}=\mathrm{O}$ bond in $\alpha, \beta$-unsaturated aldehydes and ketones to the corresponding saturated aldehydes/ketones or unsaturated alcohols has broad applications in the synthesis of many drugs, medical intermediates and fine chemicals. ${ }^{9-11}$ Although various catalyst systems for this selective hydrogenation reaction have been extensively reported, until now only a few catalytic systems affording the $\mathrm{C}=\mathrm{C}$ bond hydrogenation product with good selectivity and recyclability were reported. ${ }^{12-19}$ Encouraged by our pervious exciting results of TPSCS and with the aim to expand the application scopes of this system, in this paper, TPS- $\mathrm{Rh}_{\text {nano }}$ was explored firstly for selective hydrogenation of $\alpha, \beta$-unsaturated aldehydes and ketones.

TPS-Rh $\mathrm{h}_{\text {nano }}$ catalyst was prepared by hydrogen reduction of $\mathrm{RhCl}_{3} \cdot 3 \mathrm{H}_{2} \mathrm{O}$ using $\mathrm{IL}_{\mathrm{PEG}}(n=22)$ as a stabilizer (see ESI $\uparrow$ for details). Fig. 2 shows the UV-visible absorption spectra of the solution of $\mathrm{RhCl}_{3}$ and $\mathrm{IL}_{\mathrm{PEG}}(n=22)$ before and after reduction. Apparently, after reduction the characteristic absorption peak of Rh (III) at $520 \mathrm{~nm}$ disappeared completely, which indicated the formation of $\mathrm{Rh}^{0}{ }^{20}$ Further analysis by TEM revealed that the $\mathrm{Rh}$ nanoparticles stabilized by $\mathrm{IL}_{\mathrm{PEG}}(n=22)$ dispersed very well with an average particle size of $1.7 \pm 0.2 \mathrm{~nm}$ (Fig. 3a). For

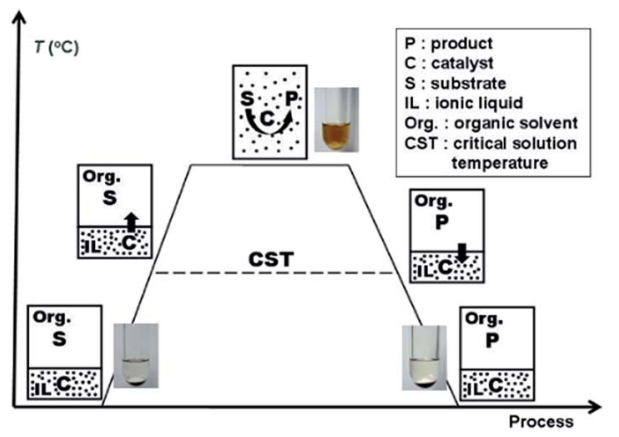

Fig. 1 Schematic diagram of thermoregulated phase-separable catalytic system. 


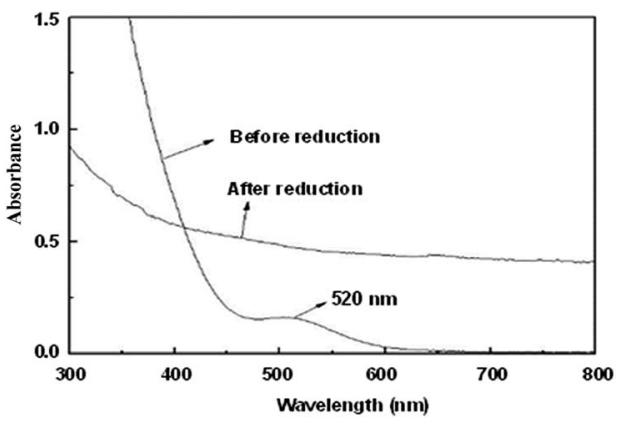

Fig. 2 UV-visible absorption spectra of the solution of $\mathrm{RhCl}_{3}$ and IL $\mathrm{L}_{P E G}$ $(n=22)$ before and after reduction.

comparison, TOAB (tetraoctyl ammonium bromide) with electrostatic stabilization, ${ }^{21-24}$ MPEG-1000 (polyethylene glycol monomethylether 1000) with steric stabilization ${ }^{25-27}$ and the mixture of TOAB and MPEG-1000 with electrosteric stabilization were used separately as a stabilizer for Rh nanoparticles under the same conditions. The results showed that Rh black could be seen by the naked eye when TOAB acted independently as stabilizer. Meanwhile, the nonuniform dispersion or even obvious aggregation was observed for nanoparticles prepared from MPEG-1000 or the mixture of TOAB and MPEG-1000 (Fig. $3 \mathrm{~b}$ and c). Therefore, the formation of homogeneousdispersed $\mathrm{Rh}$ nanoparticle catalyst stabilized by $\operatorname{IL}_{\mathrm{PEG}}(n=22)$ was attributed to the perfect combination of electrostatic and
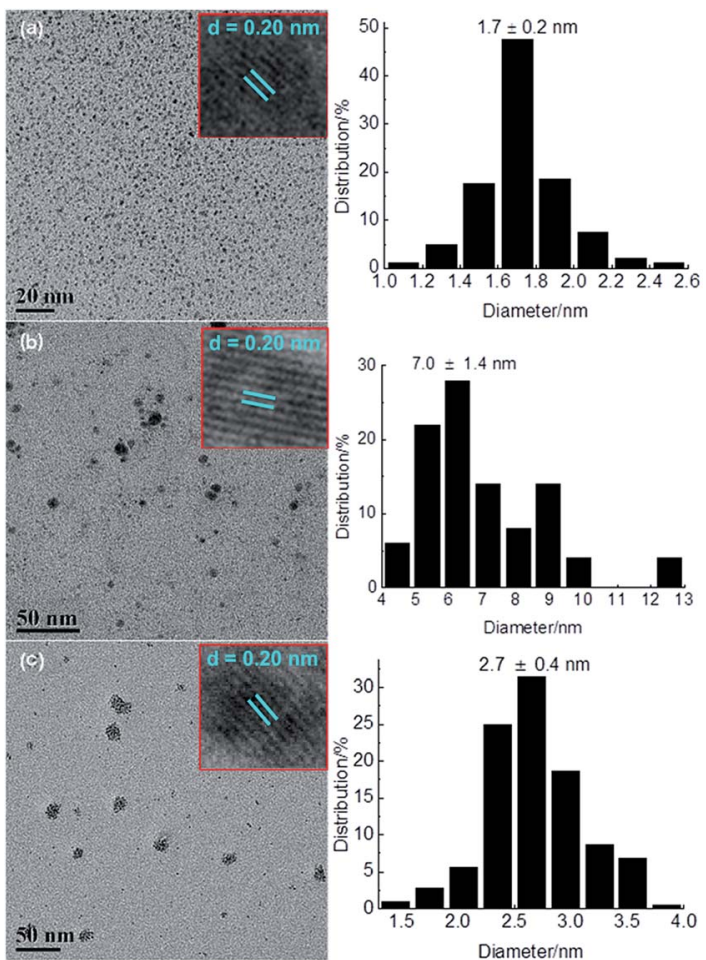

Fig. 3 TEM images and particle size histograms of Rh nanoparticles prepared by different stabilizers: (a) electrosteric stabilization by ILPEG ( $n=22$ ); (b) steric stabilization by MPEG-1000; (c) electrosteric stabilization by the mixture of TOAB and MPEG-1000 (200 particles). steric stabilizations. Furthermore, all HRTEM images of Rh nanoparticles prepared by different stabilizers showed that the lattice fringes spacing of $0.20 \mathrm{~nm}$ were close to the (111) facet of $\mathrm{Rh}$ nanoparticles.

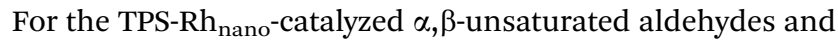
ketones, cinnamaldehyde was chosen as a representative substrate to evaluate the catalyst performance and by varying temperature, hydrogen pressure, reaction time and molar ratio of cinnamaldehyde to $\mathrm{Rh}$ to identify the optimum reaction conditions (Table 1). The effect of reaction temperature was explored firstly in the range of $30-70{ }^{\circ} \mathrm{C}$. When temperature was increased from 30 to $60{ }^{\circ} \mathrm{C}$, the conversion of cinnamaldehyde increased from $12 \%$ to $99 \%$, while the selectivity of the hydrogenation product of $\mathrm{C}=\mathrm{C}$ bond remained $>99 \%$ all the time (entries 1-4). With a further increase in temperature to $70{ }^{\circ} \mathrm{C}$, the selectivity towards the hydrogenation product of $\mathrm{C}=\mathrm{C}$ bond dropped to $94 \%$ although almost total conversion was observed (entry 5). And the by-product was proved to be the hydrogenation product of both $\mathrm{C}=\mathrm{C}$ and $\mathrm{C}=\mathrm{O}$ bonds. Further optimisation was the role of hydrogen pressure on the reaction and the results indicated that the conversion of cinnamaldehyde improved obviously with increasing hydrogen pressure from 0.1 to $1.0 \mathrm{MPa}$ and $99 \%$ conversion was achieved at $1.0 \mathrm{MPa}$ (entries 4,6 and 7). When the hydrogen pressure was further increased to $1.5 \mathrm{MPa}$, the conversion reached $>99 \%$ (entries $4 v s$. 8). It was clear that prolonging the reaction time was in favour of improving the conversion of cinnamaldehyde (entries 4 and 9-11). In addition, we found that the conversion of cinnamaldehyde declined apparently when the molar ratio raised from 500 to 2000 (entries 4 and 12-14). For the sake of product separation and catalyst recycling, the best molar ratio of cinnamaldehyde to Rh was chosen to be 500 in our studies. It's worth mentioning that the selectivity towards the hydrogenation product of $\mathrm{C}=\mathrm{C}$ bond in cinnamaldehyde was totally unaffected by hydrogen pressure, reaction time and the molar ratio of cinnamaldehyde to $\mathrm{Rh}$. Under the optimized reaction conditions, the conversion of cinnamaldehyde and the selectivity of the $\mathrm{C}=\mathrm{C}$ bond hydrogenation product were all $>99 \%$. The TOF was $245 \mathrm{~h}^{-1}$.

The reusability is a significant parameter in evaluation of a catalyst, especially for transition metal nanoparticle catalysts. Therefore, the reusability of TPS- $\mathrm{Rh}_{\text {nano }}$ catalyst for selective hydrogenation of cinnamaldehyde was examined under the above-mentioned optimum conditions. After reaction, the lower TPS- $\mathrm{Rh}_{\text {nano }}$ catalyst phase was simply separated from the product phase by simple phase separation and reused directly in the next catalytic cycle. As shown in Fig. 4, the TPS- $\mathrm{Rh}_{\text {nano }}$ catalyst could be used eight times without evident loss in conversion and selectivity. Comparison of the TEM images of $\mathrm{Rh}$ nanoparticles between newly prepared and after eight cycles revealed that the particle size increased slightly from original 1.7 to current $2.2 \mathrm{~nm}$ (Fig. 3a vs. Fig. 5). In addition, the oxidation state and recyclability of the $\mathrm{TPS}-\mathrm{Rh}_{\text {nano }}$ catalyst basically remained before and after the catalytic reactions judging from XRD and XPS (Fig. S1 and S2, see the ESI $\uparrow$ for details). Moreover, ICP-AES analysis of the upper organic phase after the first run indicated that the leaching of Rh was only 
Table 1 Selective hydrogenation of cinnamaldehyde using TPS- $\mathrm{Rh}_{\text {nano }}$ as catalyst ${ }^{a}$

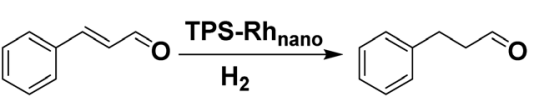

\begin{tabular}{|c|c|c|c|c|c|c|c|}
\hline Entry & $T\left({ }^{\circ} \mathrm{C}\right)$ & $P_{\mathrm{H}_{2}}(\mathrm{MPa})$ & $t(\mathrm{~h})$ & $\mathrm{S} / \mathrm{C}\left(\mathrm{mol} \mathrm{mol}^{-1}\right)$ & Conv. $^{b}(\%)$ & $\operatorname{Sel}^{c}(\%)$ & $\operatorname{TOF}^{d}\left(\mathrm{~h}^{-1}\right)$ \\
\hline 1 & 30 & 1.0 & 2.0 & 500 & 12 & $>99$ & 30 \\
\hline 2 & 40 & 1.0 & 2.0 & 500 & 48 & $>99$ & 119 \\
\hline 4 & 60 & 1.0 & 2.0 & 500 & 99 & $>99$ & 245 \\
\hline 5 & 70 & 1.0 & 2.0 & 500 & $>99$ & 94 & 233 \\
\hline 6 & 60 & 0.1 & 2.0 & 500 & 9 & $>99$ & 22 \\
\hline 9 & 60 & 1.0 & 0.5 & 500 & 22 & $>99$ & 218 \\
\hline 10 & 60 & 1.0 & 1.0 & 500 & 65 & $>99$ & 322 \\
\hline 11 & 60 & 1.0 & 1.5 & 500 & 91 & $>99$ & 300 \\
\hline 12 & 60 & 1.0 & 2.0 & 1000 & 87 & $>99$ & 431 \\
\hline 13 & 60 & 1.0 & 2.0 & 1500 & 65 & $>99$ & 483 \\
\hline 14 & 60 & 1.0 & 2.0 & 2000 & 54 & $>99$ & 535 \\
\hline
\end{tabular}

${ }^{a}$ Reaction conditions: $\mathrm{IL}_{\mathrm{PEG}} 0.3 \mathrm{~g}$ (containing $2.6 \times 10^{-3} \mathrm{mmol}$ rhodium), toluene $(3.5 \mathrm{~g}), n$-heptane $(0.7 \mathrm{~g})$. The miscibility temperature of the system is $60{ }^{\circ} \mathrm{C} .{ }^{b}$ Determined by GC with cyclohexane $(0.2 \mathrm{~g})$ as internal standard. ${ }^{c}$ Selectivity of the $\mathrm{C}=\mathrm{C}$ bond hydrogenation product, the only by-product was the hydrogenation product of both $\mathrm{C}=\mathrm{C}$ and $\mathrm{C}=\mathrm{O}$ bonds. ${ }^{d}$ Turnover frequency (TOF): moles of main product per mole of rhodium per hour.

$0.05 \mathrm{wt} \%$, and from the second run on the leaching of Rh was lower than the detection limit. These results again confirmed that the TPS-Rh $\mathrm{h}_{\text {nano }}$ catalyst had good stability, catalytic activity, selectivity and recyclability.

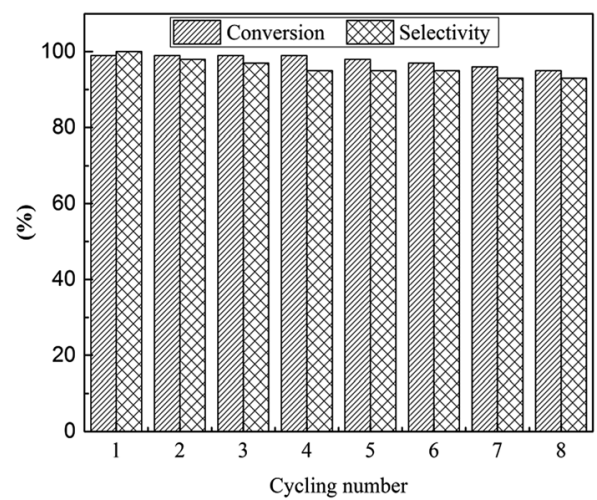

Fig. 4 Recyclability of the TPS- $R \mathrm{~h}_{\text {nano }}$ catalyst for selective hydrogenation of cinnamaldehyde.
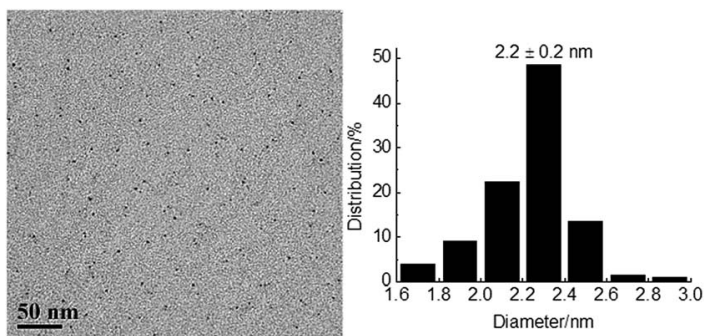

Fig. 5 TEM image and particle size histogram of Rh nanoparticles after eight catalytic cycles (200 particles).
Table 2 Selective hydrogenation of different $\alpha, \beta$-unsaturated aldehydes and ketones catalyzed by the TPS- $\mathrm{Rh}_{\text {nano }}{ }^{a}$

Entry Substrate

${ }^{a}$ Reaction conditions: $\mathrm{IL}_{\mathrm{PEG}} 0.3 \mathrm{~g}\left(n=22\right.$, containing $2.6 \times 10^{-3} \mathrm{mmol}$ $\mathrm{Rh}$ ), toluene $3.5 \mathrm{~g}, n$-heptane $0.7 \mathrm{~g} ; T=60^{\circ} \mathrm{C}, P_{\mathrm{H}_{2}}=1.0 \mathrm{MPa}, t=2.0 \mathrm{~h}$, substrate $/ \mathrm{Rh}=500$, the miscibility temperature of the system is $60^{\circ} \mathrm{C}$. The conversion was determined by GC with cyclohexane $(0.2 \mathrm{~g})$ as internal standard; the selectivity was the corresponding hydrogenation product of $\mathrm{C}=\mathrm{C}$ bond.

In order to evaluate the generality of the above TPS- $\mathrm{Rh}_{\text {nano }}$ catalyst, the selective hydrogenation of different $\alpha, \beta$-unsaturated aldehydes and ketones, such as crotonaldehyde, benzylideneacetone and 2-cyclohexen-1-one, were also explored. Under the optimized reaction conditions, all substrates afforded their corresponding hydrogenation products of $\mathrm{C}=\mathrm{C}$ bond with $>99 \%$ conversion and $>99 \%$ selectivity (Table 2 ).

\section{Conclusions}

In summary, the TPS-Rh $\mathrm{h}_{\text {nano }}$ catalyst was employed firstly for the selective hydrogenation of $\alpha, \beta$-unsaturated aldehydes and ketones. Excellent selectivity ( $>99 \%$ ) at the site of $\mathrm{C}=\mathrm{C}$ bond 
with conversion of $>99 \%$ was achieved. More excitingly, the catalyst could be easily separated from the product by simple phase separation and reused directly for eight times without evident loss in activity and selectivity.

\section{Conflicts of interest}

There are no conflicts to declare.

\section{Acknowledgements}

This work was supported by the National Natural Science Foundation of China (21173031, 21373039).

\section{Notes and references}

1 A. Roucoux, J. Schulz and H. Patin, Chem. Rev., 2002, 102, 3757.

2 S. Shylesh, V. Schünemann and W. R. Thiel, Angew. Chem., Int. Ed., 2010, 49, 3428.

3 N. Koukabi, E. Kolvari, M. A. Zolfigol, A. Khazaei, B. S. Shaghasemi and B. Fasahati, Adv. Synth. Catal., 2012, 354, 2001.

4 B. Karimi, F. Mansouri and H. M. Mirzaei, ChemCatChem, 2015, 7, 1736.

5 Y. Xu, Y. Wang, Y. Zeng, Y. Song, J. Zhao, J. Jiang and Z. Jin, Chin. J. Catal., 2012, 33, 1871.

6 Y. Zeng, Y. Wang, J. Jiang and Z. Jin, Catal. Commun., 2012, 19,70 .

7 Y. Zeng, Y. Wang, Y. Xu, Y. Song, J. Jiang and Z. Jin, Catal. Lett., 2013, 143, 200.

8 Y. Xu, Y. Wang, K. Li, M. Niu, Y. Zeng, J. Jiang and Z. Jin, J. Nanosci. Nanotechnol., 2013, 13, 5048.

9 M. Bartok and A. Molnar, The Chemistry of Double-bonded Functional Groups, Wiley, New York, 1997.

10 D. D. Falcone, J. H. Hack and R. J. Davis, ChemCatChem, 2016, 8, 1074.
11 M. Tamura, D. Yonezawa, T. Oshino, Y. Nakagawa and K. Tomishige, ACS Catal., 2017, 7, 5103.

12 N. M. Callis, E. Thiery, J. L. Bras and J. Muzart, Tetrahedron Lett., 2007, 48, 8128.

13 S. Morrissey, I. Beadham and N. Gathergood, Green Chem., 2009, 11, 466.

14 V. R. Landaeta, F. López-Linares, R. Sánchez-Delgado, C. Bianchini, F. Zanobini and M. Peruzzini, J. Mol. Catal. A: Chem., 2009, 301, 1.

15 X. Ni, B. Zhang, C. Li, M. Pang, D. Su, C. T. Williams and C. Liang, Catal. Commun., 2012, 24, 65.

16 M. Niu, Y. Wang, W. Li, J. Jiang and Z. Jin, Chin. J. Catal., 2013, 34, 674.

17 Y. Zhang, X. Yang, Y. Zhou, G. Li, Z. Li, C. Liu, M. Bao and W. Shen, Nanoscale, 2016, 8, 18626.

18 W. Li, Y. Wang, P. Chen, M. Zeng, J. Jiang and Z. Jin, Catal. Sci. Technol., 2016, 6, 7386.

19 S. Doherty, J. G. Knight, T. Backhouse, E. Abood, H. Alshaikh, I. J. S. Fairlamb, R. A. Bourne, T. W. Chamberlain and R. Stones, Green Chem., 2017, 19, 1635.

20 W. Tu, H. Liu and K. Y. Liew, J. Colloid Interface Sci., 2000, 229, 453.

21 V. Cimpeanu, M. Kočevar, V. I. Parvulescu and W. Leitner, Angew. Chem., Int. Ed., 2009, 48, 1085.

22 N. Podoliak, D. Bartczak, O. Buchnev, A. G. Kanaras and M. Kaczmarek, J. Phys. Chem. C, 2012, 116, 12934.

23 L. M. Rossi, L. L. R. Vono, M. A. S. Garcia, T. L. T. Faria and J. A. Lopez-Sanchez, Top. Catal., 2013, 56, 1228.

24 Y. Yu, B. W. Goodfellow, M. R. Rasch, C. Bosoy, D.-M. Smilgies and B. A. Korgel, Langmuir, 2015, 31, 6924.

25 H. Bönnemann and R. M. Richards, Eur. J. Inorg. Chem., 2001, 2001, 2455.

26 Z. Sun, Y. Wang, M. Niu, H. Yi, J. Jiang and Z. Jin, Catal. Commun., 2012, 27, 78.

27 M. Niu, Y. Wang, P. Chen, D. Du, J. Jiang and Z. Jin, Catal. Sci. Technol., 2015, 5, 4746. 